\title{
Knowledge, Attitudes and Practices of Nurses, Regarding Hepatitis B Prevention at Public Hospital Lahore
}

\author{
Sumaira Rehman*, Afsar Ali, Naseem Rooman, Najma Sardar \\ National College of Nursing, The University of Lahore, Lahore, Pakistan.
}

\begin{abstract}
Background: Occupational exposure occurs frequently among Health Care Workers (HCWs). The most serious occupational health hazard faced by HCWs worldwide is exposure to Hepatitis B Virus (HBV). Having enough knowledge and proper attitudes toward this infection is crucial in prevention of occupational hepatitis infection.
\end{abstract}

\begin{abstract}
Methods: This cross sectional descriptive study conducted to assess knowledge, attitude and practice of nurses regarding Hepatitis B prevention and control at Services hospital Lahore. In this study well-structured close ended questionnaire adopted from a study, knowledge, attitudes and practices of healthcare workers at the princess Marina hospital in Botswana regarding Hepatitis B prevention and control will be used (Machiya, 2011). The study was conducted in Services hospital among 200 nurses to assess knowledge, attitudes and practices of Nurses, regarding Hepatitis B prevention and control at a tertiary care hospital Lahore.
\end{abstract}

Results: It was found that most of the nurses were enough knowledge, positive attitude and better practice among nurses. Mostly, nurses response are positively very rare participant response are negative. The knowledge of Hepatitis B infection prevention, $81 \%$ of the participants knew that Hepatitis B infection can be transmitted by carriers. Majority $89.5 \%$ knew that Hepatitis B infection cannot be spread through casual contact. Majority knew that open wound, contaminated blood and body fluids, unsterilized syringes, needles and surgical instruments could easily transmit the Hepatitis B infection. Among the participants $86.5 \%$ had knowledge that vaccines can prevent Hepatitis B. $23 \%$ of the participants had negative attitude towards Hepatitis B. The attitude was positive among 55.6\% participants and 54.2\% participants were performing safe preventive practices.

Keywords: Knowledge, Attitude, Practice, Hepatitis B, Prevention, Control, Nurses.

\section{INTRODUCTION}

Hepatitis is a disease of inflammatory in nature attacking liver, a vital organ in the body. Some patients remain asymptomatic while others develop symptoms and signs like yellow skin discoloration, whites of eyes, decrease in appetite, tiredness and abdominal pain etc. [1]. Hepatitis B is an infection common worldwide as a serious healthcare problem more prominent in developing countries [2].

Worldwide there are greater than 300 million people carry the infection of virus where $90 \%$ are from the developing countries. Moreover, $75 \%$ are from the countries of Asia where 8 to $15 \%$ of the population are infected with some kinds of virus [3]. Hepatitis B infection is preventable disease, through safe and appropriate following of vaccination as per worldwide recommendation. The proper operation of vaccines is still questionable in many parts of the world including our country Pakistan. Especially, the health care workers are having insufficient protection. Health care workers are aware of all consequences and even then they have very low ratio of vaccination. Many vaccinated persons having the risk of contracting Hepatitis B infection 6-30\% caused by HBV infected needles [4].

*Address correspondence to this author at the National College of Nursing, The University of Lahore, Lahore, Pakistan.

E-mail: sumairarehman82@gmail.com
Globally, in all hospitals and health care organizations, infection remains a huge problem and a greater public health concern. It is considered a very serious issue because it contributes to large number of morbidity, mortality and increased cost [5]. The aim of infection prevention measures is to make sure to protect the vulnerable population, who are at greater risk of acquiring the infection of Hepatitis B virus. These risk groups can be from community as well as hospitals during treatment [5].

In developing countries like Pakistan, the prevalence of Hepatitis B is increasing and the preventive measures are not practiced properly by nurses and doctors and other health care professionals [6]. Annual deaths from the infection of Hepatitis B are around 1 million and every year 4.5 millions of new incidences are reported globally [7]. Nurses and other health care workers are always at a greater risk of getting the Hepatitis B virus because they are always exposed to sharp injury, and body fluids of patients [8].

It is observed that Nurses and physicians are every time directly in contact with patients such as injections, transfusion of blood, and surgical site care and become vulnerable to acquire any infection [9]. Health care providers should be aware of the dangers of such infections and should take proper precautionary measures [10]. Along with the doctors and nurses, the other trainees such as medical and nursing students 
are also exposed to high magnitude of Hepatitis B infection where the risk of accidental injury becomes very high due to low experience and skills [11].

In the world a great majority are at the risk of getting Hepatitis $\mathrm{B}$ infection. The reason for this high risk include routine contact with blood, no awareness about the prevention and control measures, negative attitude and lack of practices. Nearly 400 million people globally have Hepatitis B infection where the Asian people are having the highest rates [12].

Centre for Disease control found that chronic hepatitis B prevalence among adult population in the South East Asia such as Thailand shows hepatitis prevalence about $5-7 \%$. This ratio of chronic Hepatitis B among adult varies around the globe. The prevalence in the west region of Africa is found to be the highest which is more than $8 \%$ among the adult living there. In the other regions of Africa, the central Asia and south east Asia the prevalence of Hepatitis B among the adult population is ranging from $5-7 \%$ of the total adult population [13].

The ways to get the Hepatitis B infection are not similar everywhere. The Asian people and the non-Asian people have different mechanisms of getting the infection. Well known and prominent reasons for non-Asian are unprotected sex, while vertical transmission is common in Asian. Moreover health care activities such as handling patients' blood, wound etc are the causes in health care professionals and Nurses [14].

A study conducted by Pakistan Medical Research Council where the prevalence of Hepatitis B was assessed all over Pakistan in all provinces. The data was taken in 2007-2008. 47000 individuals were screened top see the prevalence of Hepatitis B among them. The prevalence of Hepatitis B was found as $2.5 \%$ while a combine Hep B and Hep C prevalence was $7.6 \%$ among the population. This findings give an estimation that about 13 million Pakistani are suffering from Hepatitis B and Hepatitis C [15].

In another research study, 3533 children were screened for Hepatitis B. Among the study participants the overall Hepatitis B infection rate was $3.3 \%$ among the participants. Hepatitis B infection was found to be associated with therapeutic injections, where the prevalence was high among the therapeutic injection users [Odd Ratio OR $=2.2 ; 95 \%$ Confidence Interval CI: 1.3-3.6] [16].

Different researchers conducted studies to assess the knowledge, attitude and practices of nurses and other health care workers about the prevention and control of Hepatitis B. There are few studies conducted at Bangladesh and the findings are given below. The findings of one study reveal that $67.3 \%$ of the study participants had adequate knowledge about the prevention and control of Hepatitis B infection but in contrast the preventive practices were not satisfactory. It was found that only $49.3 \%$ of the nurses were following good preventive practices. When bivariate analysis was done, it showed association Hepatitis B preventive practices with different factors such as income of the participants, their age, religion of the participants etc. $(\mathrm{P}<0.05)[4]$.

Another study conducted at Bangladesh also studied Hepatitis $\mathrm{B}$ prevention and control. It was found that majority of the participants have not taken Hepatitis B vaccine. The vaccination status was found significantly associated with education level of the participants $(p-0.000)$ and implementation of policy in hospitals [17].

\section{Aims of the Study}

The overall purpose of this study is to assess the awareness of nurses about the prevention of Hepatitis B infection at hospitals. The attitude and practices will also be determined through this study.

\section{Significance of the Study}

The findings of this current study might help the authorities to review the education curriculum of nurses trained during the study or during the clinical duties. Also, the findings of this study will be helpful to the administrators and clinical experts to have a critical look and revise if need their work place safety regulations. It might help them to the effective introduction of few needed vaccinations among all health care workers. At the last this study will be helpful to have very safe work place practices at clinical areas, because the health care professionals will have an awareness of the safe working methods.

\section{METHODS}

\section{Setting}

The site of this research study was the Services Hospital Lahore, which a huge tertiary care hospital of the Punjab government.

\section{Research Design}

A Descriptive cross sectional survey design was used to assess the knowledge, attitude and practices of nurses working at Services hospital Lahore.

\section{Population}

The participants of this study were the registered nurses working at the Services hospital Lahore.

\section{Sampling}

For recruiting the study participants, a convenient non probability sampling methods was applied. 


\section{Research Instrument}

As well-structured, close ended questionnaire adopted from a previous study of knowledge of Hepatitis B, attitudes towards Hepatitis B and practices towards Hepatitis B prevention among healthcare workers at the Princess Marina Hospital in Botswana, regarding Hepatitis B prevention and control will be used [18]. The knowledge about Hepatitis B prevention among nurses and its control was measured through 14 questions. The total knowledge scores for each nurse is further divided into poor (Having score 5 or less), moderate (score 6-10) and good knowledge (score 11-14). The attitude of Nurses will be measured with the help of 9 questions through liker scale strongly agree to strongly disagree. +2 score was for strongly agree and -2 for strongly disagree. Maximum score was +18 and minimum -18 . Negative attitude (score -7 to- 18 ), neutral attitude (score -6 to +6 ) and positive attitude +7 to +18 .

\section{Data Gathering Procedure}

The questionnaire was distributed to the participants in printed form where they answered all the question according to their own understanding. A time of about 30 minutes was given to fill the questionnaires. Then the filled questionnaires were collected.

\section{Methods Used to Analyze Data}

Data analysis was done by SPSS version 21. Statistical computer software for data analysis. The study was descriptive study and all the descriptive statistics were obtained through the SPSS software.

\section{Study Timeline}

The data was collected from February, 2018 to April, 2018.

\section{Ethical Consideration}

Permission was taken from relevant HOD via permission letter, and from Ethical Review Board Committee of National College a for conduct research. Consents was taken from all the participants and free hand was given to the participants to take part in the study or refused to participate, participants was also be the right to mentioned name or not. Enough information of research was provided to participants with help of full consent and this was achieved via a consent form attach to the questionnaire. Confidentiality was considered by informing participants. The right of participants was protected by Nuremberg Code of Ethics.

\section{RESULTS}

\section{Profile of the Respondents}

Respondents were taken from different selected areas of Services Hospital Lahore.

Table 1. Demographic Data Results.

\begin{tabular}{|c|c|c|}
\hline Variables & Category & Percent \\
\hline Gender & Female & 100 \\
\hline \multirow{2}{*}{ Age } & $21-25 \mathrm{yrs}$ & 27.3 \\
& $26-30 \mathrm{yrs}$ & 48.7 \\
& $31-35 \mathrm{yrs}$ & 24 \\
\hline Experience of the & $1-5$ years & 37.3 \\
participants & 6-10 years & 45.3 \\
& $11-15$ years & 16.7 \\
& Above 15 years & 0.7 \\
\hline Education & Nursing Diploma & 42 \\
& Diploma plus specialization & 42.7 \\
& BSN and above & 15.3 \\
\hline
\end{tabular}

Table 1 shows the findings of Demographic data and reveals that all $100 \%$ of the study participants were Females and there were no males recruited. It was also found that $27.3 \%$ of the participants were age $21-25$ years, $48.7 \%$ were age $26-30$, and $24 \%$ participants were in age group $31-35$ years. Regarding experience of the study participants, $37.3 \%$ had experience 1 5 years, $45.3 \%$ were $6-10$ years of experience and $16.7 \%$ participants had experience greater than 11-15 years. Among the participants, $42 \%$ were having only Diploma General Nursing qualification, $42.7 \%$ had General Nursing plus post basic specialization and $15.3 \%$ of the nurses had BSN or high education.

Table 2. Awareness of Hepatitis B Prevention Precautions.

\begin{tabular}{|c|c|c|c|c|}
\hline S. No. & Statement & True & False & Don't Know \\
\hline 1. & $\begin{array}{c}\text { Universal should be especially used only when dealing with some known } \\
\text { Hepatitis B virus positive patients }\end{array}$ & $80 \%$ & $20 \%$ & $0 \%$ \\
\hline 2. & $\begin{array}{l}\text { Consumption of spoilt rotten food can be the cause of Hepatitis B virus } \\
\text { infection }\end{array}$ & $72.1 \%$ & $19.2 \%$ & $8.7 \%$ \\
\hline 3. & Needles recap should be recommended after use & $78.1 \%$ & $10 \%$ & $11.9 \%$ \\
\hline 4. & Hepatitis B is transmitted just like nosocomial infection & $18.3 \%$ & $73.1 \%$ & $8.6 \%$ \\
\hline 5. & After vaccination for Hepatitis B, blood confirmatory tests are not necessary & $18.3 \%$ & $73.1 \%$ & $8.7 \%$ \\
\hline 6. & $\begin{array}{l}\text { Majority vaccinated persons achieve } 100 \% \text { protection against Hepatitis B } \\
\text { virus }\end{array}$ & $11.4 \%$ & $79.4 \%$ & $9.20 \%$ \\
\hline 7. & Hepatitis B virus is about 100 times more infectious than HIV & $58 \%$ & $31.5 \%$ & $1.8 \%$ \\
\hline
\end{tabular}


Table 2. (Continued)

\begin{tabular}{|c|c|c|c|c|}
\hline S. No. & Statement & True & False & Don't Know \\
\hline 8. & $\begin{array}{c}\text { An antibody level of } 10 \mathrm{mIU} / \mathrm{ml} \text { is considered essential for protection } \\
\text { against Hepatitis B virus }\end{array}$ & $20.1 \%$ & $69.4 \%$ & $10.5 \%$ \\
\hline 9. & $\begin{array}{l}\text { After exposure to HBV receiving the first dose of Hepatitis B vaccine and } \\
\text { Hepatitis B immunoglobulin within a week can reduce chances of infection }\end{array}$ & $16 \%$ & $75.3 \%$ & $8.7 \%$ \\
\hline 10. & $\begin{array}{l}\text { Once a patient has been vaccinated against Hepatitis B they should not be } \\
\text { considered as a possible source of Hepatitis B }\end{array}$ & $8.7 \%$ & $80.8 \%$ & $1.8 \%$ \\
\hline 11. & A person who has been vaccinated, can infect others & $60 \%$ & $25 \%$ & $15 \%$ \\
\hline 12. & Complete vaccination of Hepatitis B required three doses. & $47.9 \%$ & $8.7 \%$ & $43.4 \%$ \\
\hline 13. & The duration of protection after successful vaccination is at least 15 years & $28.8 \%$ & $1.8 \%$ & $60.7 \%$ \\
\hline 14. & Hepatitis B virus can be sexually transmitted & $74 \%$ & $8.6 \%$ & $17.4 \%$ \\
\hline
\end{tabular}

Table 2 tell us about standard precautions such as hand washing, appropriate wearing of gloves, use of some barriers like gown and other aseptic techniques. It is suggested that the above mentioned techniques should be used in case of known Hepatitis B virus positive patients' where $80 \%$ participants score true and 20\% participants' score are false. Another variable show the percentage of the participants about Consuming spoilt rotten food can cause Hepatitis B infection where $72.1 \%$ participants scored true and $19.2 \%$ participants scored as false. Regarding the statement that whether Needles recap should be recommended after use or not where $78.1 \%$ said true, $9 \%$ said False and $11.9 \%$ participants said they don't know. On a statement, that Hepatitis B infection is transmitted just like nosocomial infection where $18.3 \%$ said true, $73.1 \%$ said false and $8.6 \%$ said they don't know. The next variable shows, the percentage of the participants about after Hepatitis
$B$ vaccination, there is no need to have blood test to confirm immunity against Hepatitis B that $18.3 \%$ participants score true and $73.1 \%$ participants score are false. The percentage of the participants about' a great majority, $90 \%$ people who are vaccinated achieve full safety and protection against Hepatitis B where $11.4 \%$ participants scored true and $79.9 \%$ participants scored false. On a statement, that when once a patient has been vaccinated against Hepatitis B they should not be considered as a possible source of Hepatitis B. In response $8.7 \%$ said true, $80.8 \%$ said false and $1.8 \%$ said they don't know about it. According to another statement, a person who has been vaccinated, can infect others, $60 \%$ said it true, $25 \%$ considered it false and $15 \%$ did not know about it. To a statement, that Hepatitis B virus can be sexually transmitted, $74 \%$ answered true, $8.6 \%$ said false and 17 said they don't know.

Table 3. Attitude of Hepatitis B Prevention Precautions.

\begin{tabular}{|c|c|c|c|c|c|c|}
\hline S. No. & Statement & SD & D & N & A & SA \\
\hline 1. & $\begin{array}{c}\text { Vaccination against HBV should be made available to all healthcare } \\
\text { workers for free. }\end{array}$ & $2.7 \%$ & $17.4 \%$ & $22.8 \%$ & $48.4 \%$ & $0 \%$ \\
\hline 2. & $\begin{array}{c}\text { Hepatitis B vaccination is too expensive for me to purchase; if it is not } \\
\text { free I will not purchase it. }\end{array}$ & $48.4 \%$ & $17.8 \%$ & $20.5 \%$ & $4.6 \%$ & $8.7 \%$ \\
\hline 3. & I do not trust vaccinations & $4.6 \%$ & $8.7 \%$ & $1.4 \%$ & $25.6 \%$ & $51.1 \%$ \\
\hline 4. & Vaccination is against my religion / traditional beliefs & $4.6 \%$ & $9.1 \%$ & $4.6 \%$ & $12.8 \%$ & $60.3 \%$ \\
\hline 5. & $\begin{array}{c}\text { Every patient should be treated as if they are carrying a blood borne } \\
\text { pathogen. }\end{array}$ & $5 \%$ & $7.3 \%$ & $2.7 \%$ & $14.6 \%$ & $61.6 \%$ \\
\hline 6. & It is important to wash your hands after any contact with each patient & $5 \%$ & $9.6 \%$ & $3.2 \%$ & $51.1 \%$ & $8.7 \%$ \\
\hline 7. & $\begin{array}{c}\text { I am not at risk for Hepatitis B because I am always careful when } \\
\text { examining patients and taking specimens }\end{array}$ & $44.7 \%$ & $22.4 \%$ & $5 \%$ & $14.6 \%$ & $9.1 \%$ \\
\hline 8. & I am not at risk for HBV because I am a healthy person & $53.9 \%$ & $13.7 \%$ & $1.4 \%$ & $11.0 \%$ & $11.4 \%$ \\
\hline 9. & My job puts me at risk of HBV infection & $51.1 \%$ & $20.5 \%$ & $5 \%$ & $9.6 \%$ & $9.6 \%$ \\
\hline
\end{tabular}

Table 3 reveals the attitude score of participants about towards the prevention of Hepatitis B infection. In response to a statement, that all vaccination should be made available to all healthcare workers for free Vaccination against HBV should be made available to all healthcare workers for free, the score of strongly disagree participants were $2.7 \%$, the score of disagree were $17.4 \%$, the score of agree participants were $22.8 \%$ and the score of strongly agree participants were $48.4 \%$. To a question that vaccination is too expensive for me to purchase; if it is not free, I will not purchase it where $48.4 \%$ strongly disagreed, $17.8 \%$ disagreed, $20.5 \%$ were neutral, $4.6 \%$ agreed and $8.7 \%$ strongly agreed. The score of participants about, I do not trust vaccinations, the score of strongly disagree participants were $4.6 \%$, the score of disagree were $8.7 \%$, the score of uncertain participants were $1.4 \%$, the score of agree participants were $25.6 \%$ and the score of strongly agree participants were $51.1 \%$. In response to a question, that every patient should be treated as if they are 
carrying a blood borne pathogen, 5\% strongly disagreed, $7.3 \%$ disagreed, $2.7 \%$ remained neutral, $14.6 \%$ agreed and $61.6 \%$ strongly agreed with the statement. The score of participants about, I am not at risk for Hepatitis B because I am always careful when examining patients and taking specimens, the score of strongly disagree participants were $44.7 \%$, the score of disagree participants were $22.4 \%$, the score of uncertain participants were $5 \%$. When the nurses were asked if their job puts them at risk of $\mathrm{HBV}$ infection, in response $51.1 \%$ strongly disagreed, 20.5\% disagreed, 5\% were neutral, $9.6 \%$ agreed and $9.6 \%$ strongly agreed with the statement.

\section{DISCUSSION}

The cross sectional analytical study describe the knowledge, attitude and practice of the service hospital nurses about Hepatitis B which result discus such as standard Precautions such as hand washing, appropriate wearing of gloves, use of some barriers like gown and other aseptic techniques. It is suggested that the above mentioned techniques should be used in case of known Hepatitis B virus positive patients where $80 \%$ participants score true and $20 \%$ participants' score are false. Another variable shows the percentage of the participants about Consuming spoilt/old rotten food can result in Hepatitis B virus infection' that $72.1 \%$ participants score true and $19.2 \%$ participants' score are false. The next variable show the percentage of the participants about after Hepatitis B vaccination, there is no need to have blood test to confirm immunity against Hepatitis B that $18.3 \%$ participants score true and $73.1 \%$ participants score are false. The percentage of the participants about' a great majority, 90\% people who are vaccinated achieve full safety and protection against Hepatitis $B$ where $11.4 \%$ participants scored true and $79.9 \%$ participants scored false. The next statement show that the score of participants about Hepatitis B virus is about 100 times more infectious than HIV' the score of true participants were $58 \%$, the score of false participants were $31.5 \%$ and $4 \%$ participants score were don't know. The attitude was positive among 55.6\% participants and 54.2\% participants were performing safe preventive practices. Result of multiple logistic regression analysis showed that working in hospital $(\mathrm{OR}=2.54 ; 95 \% \mathrm{CI}(1.12,5.75))$, working experience greater than10years $(\mathrm{OR}=3.79(95 \% \mathrm{CI}=2.33,6.17))$ and availability $\mathrm{PPE}(\mathrm{OR}=6.79(95 \% \mathrm{CI}=2.83,17.27))$ had positive association with infection prevention [5].

The score of uncertain participants were $1.4 \%$, the score of agree participants were $25.6 \%$ and the score of strongly agree participants were 51.1. The score of participants about, I am not at risk for Hepatitis B because I am always careful when examining patients and taking specimens, the score of strongly disagree participants were $44.7 \%$, the score of disagree participants were $22.4 \%$, the score of uncertain participants were $5 \%$, the score of agree participants were
$14.6 \%$ and the score of strongly agree participants were $9.1 \%$. The score of participants about, have you ever had a needle stick/ sharps injury with a used needle or other sharp instrument? the score of yes participants were $28.8 \%$, the score of no were $18.3 \%$, the score of not sure participants were $8.7 \%$. The score of participants about, did you report the needle stick Injury? The score of yes participants were $4.6 \%$, the score of no were $15.5 \%$, and the score of not sure participants were $57.5 \%$, a study was conducted at Saudi Arabia to assess the knowledge of Hepatitis B infection prevention. $81 \%$ of the participants knew that Hepatitis B infection can be transmitted by carriers. Majority $89.5 \% \mathrm{knew}$ that Hepatitis B infection cannot be spread through casual contact. Majority knew that open wound, contaminated blood and body fluids, unsterilized syringes, needles and surgical instruments could easily transmit the hepatitis b infection. Among the participants $86.5 \%$ had knowledge that vaccines can prevent Hepatitis B. $23 \%$ of the participants had negative attitude towards Hepatitis B [11].

\section{LIMITATIONS}

- Sample size was low that is 200 due to which, the findings cannot be generalized.

- Due to short time and limited past exposure to research, it was not possible to see any prospective events or detailed associations of awareness and practices.

- Convenient sampling technique was used which may have some biasness.

\section{CONCLUSION}

The study was conducted in service hospital among 150 nurses to assess Knowledge, attitudes and practices of Nurses, regarding Hepatitis B prevention and control at a tertiary care hospital Lahore, it is concluded that most of the nurses were enough knowledge, positive attitude and better practice among nurses. Mostly, nurses response are positively very rare participant response are negative tasks.

\section{CONFLICT OF INTEREST}

Declared none.

\section{ACKNOWLEDGEMENTS}

I would like to thank you to the Principal National College of Nursing, Management of National, Management of UOL and all faculty of National CON.

I am highly thankful to Allah for giving me the strength and knowledge to carry out this research work. Without Allah's blessings and providence it would not be possible to complete this research project successfully. After that, I am grateful to my parents and family members who gave me enough courage and support to complete this work. 


\section{REFERENCES}

[1] Mridha C. Assessment of Knowledge and Attitude of HBV among Secondary School and College Students of Gopalganj. Dissertation. Bangladesh: East West University 2017.

[2] Alhowaish MA, Alhowaish JA, Alanazi YH, et al. Knowledge, attitudes and practices toward prevention of hepatitis $\mathrm{B}$ virus infection among medical students at Northern Border University, Arar, Kingdom of Saudi Arabia. Electronic Physician 2017; 9(9): 5388-94 DOI: 10.19082/5388

[3] Nagpal B, Hegde U. Knowledge, attitude, and practices of Hepatitis B infection among dental students. Int J Med Sci Public Health 2016; 5(6): 1123-27. DOI: 10.5455/ijmsph.2016.03102015170

[4] Mehriban N, Ahsan G, Islam T. Knowledge and preventive practices regarding Hepatitis B among nurses in some selected hospitals of Dhaka city, Bangladesh. South East Asia J Public Health 2015; 4(1): 48-52. DOI: 10.3329/seajph.v4i1.21840

[5] Gulilat K, Tiruneh G. Assessment of knowledge, attitude and practice of health care workers on infection prevention in Health Institution Bahir Dar city administration. Sci J Public Health 2014; 2(5): 384-93. DOI: 10.11648/j.sjph.20140205.13

[6] Bello FM, Musa KA, Anne CP. Health workers' k nowledge, attitude and practice towards Hepatitis B infection in northern Nigeria. Int J Caring Sci 2016; 9(3): 939.

[7] ul Haq N, Hassali MA, Shafie AA, et al. A cross-sectional assessment of knowledge, attitude and practice among Hepatitis B patients in Quetta, Pakistan. BMC Public Health 2013; 13(1): 448. DOI: 10.1186/1471-2458-13-448

[8] Abeje G, Azage M. Hepatitis B vaccine knowledge and vaccination status among health care workers of Bahir Dar City Administration, Northwest Ethiopia: A cross sectional study. BMC Infect Dis 2015; 15(1): 30.

DOI: $10.1186 / \mathrm{s} 12879-015-0756-8$

[9] Hussain SF, Ahmad SR, Muslehuddin OM, Muslehuddin HM. Knowledge, attitude and practice regarding Hepatitis B among medical students. Int J Commun Med Public Health 2016; 3(11): 2977-81. DOI: 10.18203/2394-6040.ijcmph20163484
[10] Khan N, Ahmed SM, Khalid MM, Siddiqui SH, Merchant AA. Effect of gender and age on the knowledge, attitude and practice regarding Hepatitis $\mathrm{B}$ and $\mathrm{C}$ and vaccination status of Hepatitis B among medical students of Karachi. Pakistan. J Pak Med Assoc 2010; 60(6): 450-5.

[11] Abdela A, Woldu B, Haile K, Mathewos B, Deressa T. Assessment of knowledge, attitudes and practices toward prevention of $\mathrm{H}$ epatitis $\mathrm{B}$ virus infection among students of medicine and health sciences in Northwest Ethiopia. BMC Res Notes 2016; 9(1): 410. DOI: 10.1186/s13104-016-2216-y

[12] Ohlson E, Bladh F. Knowledge about Hepatitis B and Attitudes Towards Hepatitis B Vaccination among University Students in Thailand: A Quantitative Study. Dissertation. Thailand: Mahidol University 2015; p. 40.

[13] Thompson CA, Gomez SL, Hastings KG, et al. The burden of cancer in Asian Americans: A report of national mortality trends by Asian ethnicity. Cancer Epidemiol Biomarkers Prev 2016; 25(10): 1371-82.

DOI: 10.1158/1055-9965.EPI-16-0167

[14] Kim WR, Lake JR, Smith JM, et al. OPTN/SRTR 2013 annual data report: Liver. Am J Transplant 2015; 15(S2):1-28. DOI: $10.1111 /$ ajt.13197

[15] Ashraf S, Ahmad A, Viral hepatitis in Pakistan: Challenges and priorities. Asian Pacific J Trop Biomed 2015; 5(3): 190-1. DOI: 10.1016/S2221-1691(15)30004-6

[16] Ali SA, Donahue RM, Qureshi H, Vermund SH. Hepatitis B and Hepatitis $\mathrm{C}$ in Pakistan: Prevalence and risk factors. Int J Infect Dis 2009; 13(1): 9-19. DOI: 10.1016/j.ijid.2008.06.019

[17] Huq S, Hossain SM, Haque SMT, Akter S. Knowledge, attitude and practice on Hepatitis B infection among infected patients in a Homoeopathy Medical Center in Dhaka City, Bangladesh. South East Asia J Public Health 2016; 6(1): 27-31. DOI: 10.3329/seajph.v6i1.30341

[18] Machiya T. Knowledge, Attitudes and Practices of Healthcare Workers at the Princess Marina Hospital in Botswana, Regarding Hepatitis B Prevention and Control. Dissertation. South Africa: University of Limpopo (Medunsa Campus) 2011. 